\title{
Infopen Mulheres de 2014 e 2018: Desafios para a Pesquisa em Psicologia
}

\author{
Ramon Luis de Santana Alcântara ${ }^{1}$ \\ Carla Priscilla Castro Sousa ${ }^{1}$ \\ ${ }^{1}$ Universidade Federal do Maranhão, MA, Brasil. \\ ${ }^{1}$ Universidade Federal do Maranhão, MA, Brasil. \\ Thaís Stephanie Matos Silva ${ }^{1}$ \\ ${ }^{1}$ Universidade Federal do Maranhão, MA, Brasil.
}

Resumo: O sistema penitenciário funciona como um ponto de reflexão de várias questões históricas inerentes à formação da sociedade brasileira. Uma dessas questões se refere aos modos patriarcais que foram estabelecidas as relações de gênero no país. Nesse sentido, a partir da relevância desta realidade, há a necessidade de a Psicologia investigar o sistema prisional feminino sob a luz da produção teórica acerca das relações de gênero. Este estudo objetiva analisar comparativamente os Levantamentos Nacionais de Informações Penitenciárias Mulheres (Infopen Mulheres) de 2014 e 2018 com a finalidade de mapear e problematizar questões e desafios pertinentes à pesquisa psicológica. Para tal, utilizam-se como métodos a análise documental, como recurso válido para a investigação com dispositivos públicos, e o ensaio teórico, como uma prática de análise que busca desvelar novos saberes sobre uma dada realidade. Pontua-se que há um contexto no sistema prisional feminino marcado pelo agravamento dos problemas crônicos comuns ao masculino, em decorrência da invisibilidade das especificidades femininas. Destaca que o perfil das mulheres apenadas se constrói como uma questão interseccional, pois a grande maioria é constituída por negras, pobres, mães solteiras, que entraram no crime através de funções subalternas no tráfico. Problematiza-se que os atenuantes da vida prisional, como o desenvolvimento educacional e as atividades laborais, são subaproveitados, articulando esse problema a repercussões na dimensão psicológica das apenadas. Por fim, aponta-se que os Infopen revelam vários desafios para a pesquisa em psicologia, suscitando que a comunidade científica possa desenvolver novas pesquisas nesse campo de atuação e investigação.

Palavras-chave: Sistema Prisional, Relações de Gênero, Psicologia. 


\section{Infopen Women of 2014 and 2018: Challenges for Research in Psychology}

Abstract: The penitentiary system works as a reflection on several historical issues inherent in the formation of Brazilian society. One of these questions refers to the patriarchal ways in which gender relations have been established in the country. In this sense, based on the relevance of this reality, psychology needs to investigate the female prison system in the light of the theoretical production about gender relations. This study aims to comparatively analyze the National Survey of Women Penitentiary Information (Infopen Women) of 2014 and 2018 with the purpose of mapping and problematizing issues and challenges relevant to psychological research. For this purpose, the documentary analysis is used as a valid resource for researching public devices, and the theoretical essay, as a practice of analysis that seeks to unveil new knowledge about a given reality. It is pointed out that there is a context in the female prison system marked by the aggravation of the chronic problems common to the male, due to the invisibility of the feminine specificities. It is noted that the profile of incarcerated women is seen as an intersectional issue, since the vast majority are black, poor, single mothers, who entered the crime through subaltern functions in trafficking. It is problematic that attenuators of prison life, such as educational development and work activities, are underused, articulating this problem with repercussions on the psychological dimension of the victims. Lastly, it is pointed out that the Infopen reveal several challenges for the research in psychology, provoking that the scientific community can develop new researches in this field of investigation and practice.

Keywords: Prison System, Gender Relations, Psychology.

\section{Infopen Mujeres de 2014 y 2018: Desafíos para la Investigación en Psicología}

Resumen: El sistema penitenciario funciona como un punto de reflexión de varias cuestiones históricas inherentes a la formación de la sociedad brasileña. Una de esas cuestiones se refiere a los modos patriarcales en que se establecieron las relaciones de género en el país. En ese sentido, a partir de la relevancia de esta realidad, existe la necesidad de que la psicología investigue el sistema penitenciario femenino bajo la luz de la producción teórica acerca de las relaciones de género. Este estudio objetiva analizar comparativamente los Levantamientos Nacionales de Informaciones Penitenciarias Mujeres (Infopen Mujeres) de 2014 y 2018 con la finalidad de mapear y problematizar cuestiones y desafíos pertinentes a la investigación psicológica. Para ello, se utilizan como métodos el análisis documental, como recurso válido para la investigación con dispositivos públicos, y el ensayo teórico, como una práctica de análisis que busca desvelar nuevos saberes sobre una determinada realidad. Se señala que hay un contexto en el sistema penitenciario femenino marcado por el agravamiento de los problemas crónicos comunes al masculino, como consecuencia de la invisibilidad de las especificidades femeninas. Destaca que el perfil de las mujeres apenadas se construye como una cuestión interseccional, pues la gran mayoría está constituida por negras, pobres, madres solteras, que entraron en el crimen a través de funciones subalternas en el tráfico. Se plantea que los atenuantes de la vida prisional, como el desarrollo educativo y las actividades laborales, son subaprovechados, articulando ese problema a repercusiones en la dimensión psicológica de las apenadas. Por último, se señala que los Infopen revelan varios desafíos para la investigación en psicología, suscitando que la comunidad científica pueda desarrollar nuevas investigaciones en ese campo de actuación e investigación.

Palabras clave: Sistema Penitenciario, Relaciones de Género, Psicología. 


\section{Introdução}

O sistema penitenciário brasileiro enfrenta atualmente uma crise crônica, causada pelo aumento significativo nos índices de violência e criminalidade. Soma-se a isso a tendência de os sistemas de justiça priorizar as penas privativas de liberdade (Rolim, 2004), o que caminha para um maior agravamento do quadro. Essa crise configura-se como uma questão de ordem social e pública, convocando toda a sociedade a se implicar na proposição de melhoria e resolução desta problemática. Especialmente porque o contexto prisional no Brasil revela demandas de nossa histórica organização social, tais como questões étnico-raciais, de classes sociais e de relações de gênero. Essas questões entrelaçam aspectos históricos, culturais, econômicos, sociais e também psicológicos.

Diante desses aspectos, além da atuação de profissionais de Psicologia no sistema penitenciário, urge, cada vez mais, que sejam elaboradas, executadas e publicadas pesquisas em Psicologia acerca desta temática. Nessa seara, os campos de conhecimentos psicológicos, multidisciplinarmente, podem congregar novas perspectivas analíticas para a realidade prisional brasileira. Notadamente, quando tomamos a pauta da segurança pública, atrelada a um debate mais aprofundado acerca da violência perante questões sociais, atravessada pela problematização das relações de gênero no país, temos um campo muito profícuo para a Psicologia. Pensar a representação da mulher, na nossa sociedade de tradição patriarcal, associada à prática criminosa e a um sistema prisional problemático (no que se refere ao campo da justiça, dos direitos humanos e, principalmente, no aspecto da infraestrutura), abre infinitas demandas sociais para nossas investigações.

A partir de tais justificativas sociais, acreditamos que a Psicologia tem muito ainda que se desenvolver, no campo profissional, mas principalmente no campo científico, na produção de conhecimentos válidos para construir práticas e análises em prol de uma sociedade mais justa e equânime. Para que esta construção se dê de maneira qualificada e se consolide como um interessante campo de intervenção psicológica, entendemos que precisamos buscar a fomentação dessas questões como inquietações de pesquisa de profissionais e estudantes de Psicologia. Nesse sentido, este artigo busca suscitar tais inquietações, apontando um vasto universo de questões que o sistema prisional feminino está demandando à ciência psicológica.
Desta forma, objetivamos com este trabalho apontar possibilidades de pesquisa em Psicologia, pautando-se na análise de questões sociais prospectadas pela comparação analítica dos dois Levantamentos Nacionais de Informações Penitenciárias (Infopen Mulheres), de 2014 e de 2018 (Brasil, 2014; 2018), que se configuram como os únicos levantamentos específicos sobre a situação prisional feminina. Para tanto, é necessário primeiramente, contextualizar historicamente as relações de gênero no Brasil, utilizando como nexo analítico as relações de gênero no contexto prisional. Alicerçados por esta discussão, posteriormente analisamos comparativamente o Infopen Mulheres de 2014 com o de 2018, especialmente em três aspectos: 1) contexto da situação de aprisionamento feminino, a partir dos dados gerais e da infraestrutura; 2) perfil das mulheres apenadas, compreendendo-o a partir da noção de interseccionalidade; e 3) dimensões psicológicas produzidas no contexto da assistência, seja no eixo do trabalho, seja no eixo educacional. São essas análises dos Infopen Mulheres, enfatizando a relação dos dados de 2014 com 2018, que nos permite traçar os desafios contemporâneos para a Psicologia diante do debate do sistema prisional e da segurança pública, no contexto das relações de gênero.

Organizamos o texto de acordo com os objetivos supracitados. Além desta introdução, tem-se uma seção para explicar os métodos utilizados; uma para contextualizar as relações de gênero no sistema prisional; uma para analisar os Levantamentos de 2014 e 2018, nos aspectos mencionados acima; outra para ensaiar acerca dos desafios para a pesquisa em Psicologia; e por fim, as considerações finais.

\section{Método}

Metodologicamente, utilizamos a análise documental como nosso principal instrumento de coleta de dados. Compreendemos esse método a partir de Spink (2013), quando este advoga para a Psicologia Social a análise de documentos como uma metodologia válida e que fornece informações valiosas para a produção científica na área. Spink (2013, p. 82) aponta que os documentos públicos são "documentos que estão à disposição, simultaneamente traços de ação social e a própria ação social”. Os Levantamentos não só revelam dados da situação prisional das mulheres, como práticas sociais e sentidos acerca das relações de gênero no contexto da segurança pública. Em específico, com o que ele chama de "documento público seriado", como no caso dos Infopen Mulheres, Spink (2013, pp. 100- 
101) aponta que "usar documentos desse tipo, que têm uma presença no campo de interesse e que são produzidos regularmente e de forma seriada, é um excelente caminho para a compreensão da gradativa emergência, consolidação e reformulações dos saberes e fazeres". Com esse propósito, buscamos compreender como se situa as questões do aprisionamento feminino no Brasil na perspectiva do Departamento Penitenciário Nacional (Depen), assim como analisamos o que essa perspectiva posta em dados, de 2014 a 2018, nos revela como pautas de discussão.

Para além da análise documental, este artigo se propõe ensaístico, no sentido que ele se constrói em uma proposição de, a partir das análises realizadas, traçar possibilidades e desafios de pesquisa para a Psicologia. Compreendemos com Meneghetti (2011, p. 04) que “[...] ensaio é um meio de análise e elucubrações em relação ao objeto, independentemente de sua natureza ou característica. A forma ensaística é a forma como são incubados novos conhecimentos, até mesmo científicos ou pré-científicos".

Sendo assim, inicia-se com as análises concretas utilizando como fonte os Infopen Mulheres, destacando aspectos relevantes nas três categorias elaboradas (contexto prisional; perfil das mulheres apenadas; assistências e educação/trabalho). Em um segundo momento, utilizamos o recurso do ensaio teórico para pensar as questões e desafios para a pesquisa científica em Psicologia. Nesse momento, estamos produzindo novos saberes com intuito de ir além dos Levantamentos e prospectar novas possibilidades de investigação no sistema penitenciário feminino.

\section{Relações de gênero no contexto prisional}

É fato que o número de pessoas encarceradas cresceu de maneira bastante significativa e que as prisões do Brasil, ao longo do tempo, foram se tornando espaços de caráter exclusivamente punitivo em detrimento da ressocialização e efetividade dos direitos humanos, principalmente no que tange questões de gênero advindas da história patriarcal da sociedade ocidental. Nesse sentido, com o crescimento do número de mulheres apenadas, outras questões também vêm à tona, como o significado do encarceramento para as mulheres, a partir de uma perda de direitos e de dignidade, na medida em que são submetidas a condições de existência insalubres e desumanas. Com esse crescimento do número de mulheres apenadas, pode-se perceber que há um perfil comum: geralmente são mães, jovens, solteiras, com baixo nível de escolaridade e renda familiar precária (Lima, Pereira Neto, Amarante, Dias, \& Ferreira Filha, 2013).

Entretanto, nota-se claramente que esse crescimento não foi acompanhado e nem proporcional à ampliação dos ambientes prisionais. Nesse sentido, a saúde mental das apenadas é algo muitas vezes negligenciado, uma vez que, como consequência desse não acompanhamento, tem-se a indignação nas prisões, os tumultos, rebeliões, perda da liberdade e da dignidade humana. Este é um dos principais desafios que o sistema penitenciário brasileiro enfrenta: a garantia da saúde aos presos, considerando saúde não apenas como ausência de doença, mas como o bem-estar físico, mental e social, como algo maior, que se constitui a partir da garantia da proteção integral do ser humano, entre outras coisas (Lima et al., 2013).

Discutir sobre o aprisionamento de mulheres sob a ótica do feminismo nos possibilita entender este fato considerando todas as facetas que recaem sobre estas enquanto participantes de uma cultura androcêntrica e heteronormativa, principalmente quando são pobres, negras e homossexuais. Além disso, essa discussão vem a fim de desvendar as artimanhas sexistas, capitalistas e de todos os outros sistemas que estão envolvidos neste fenômeno (Carvalho, \& Mayorga, 2017).

Sabemos que o machismo é um problema estrutural, marcado e mantido por relações de poder, simbolismos, preconceitos e que ainda persiste perigosamente na nossa sociedade. Considerando isso, pode-se afirmar que muitas práticas sociais também são igualmente marcadas por esse ideário em que o sexo masculino é definido como o sexo mais forte, o mais inteligente, o mais. Dentre essas práticas, destacamos as ligadas ao poder judiciário, em especial, a questão do tratamento penal destinado às mulheres apenadas (Carvalho, \& Mayorga, 2017).

As sentenças dadas às mulheres, geralmente, são sentenças duplas: a mulher é punida pelo ato criminoso que cometeu, mas também é punida pelo fato de ser mulher, pelas suas motivações e paixões. Isso vem de preconceitos e ideias enraizados que são socialmente mantidos em relação a um equivocado "papel da mulher", de como deve agir, vestir, pensar, falar, viver. Aquele ideário de sexo frágil, influenciável e submisso, no qual o sistema penal assume a função de domesticação (Carvalho, \& Mayorga, 2017). 
A partir da realidade de mulheres apenadas, o que vem junto disso é a questão da saúde física e mental destas, se são bem assistidas, se são respeitadas enquanto seres humanos e de como que essa assistência é realizada dentro dos presídios femininos. Para falar disso, precisamos antes dar espaço aos princípios e diretrizes da Política Nacional de Atenção à Saúde da Mulher (Brasil, 2011) e ao Plano Nacional de Saúde no Sistema Penitenciário (Brasil, 2004). No primeiro está garantida a assistência à mulher negra, indígena, rural, com deficiências, e, de forma geral, a assistência à saúde da mulher em situação prisional. O segundo tem por objetivo prover assistência integral e de boa qualidade à população carcerária brasileira, contribuir para o controle de doenças dentro do ambiente prisional, promover ações e serviços de acordo com os princípios do Sistema Único de Saúde e trabalho intersetorial, democratizar conhecimentos acerca do processo saúde/doença, provocar o reconhecimento da saúde como um direito e estimular o controle social.

Segundo Silva e Ribeiro (2003), em se tratando desse cenário, as condições dos presídios - especialmente os femininos-contribuem para uma falsa ou mínima assistência e cuidado com as internas dentro dos ambientes do sistema prisional, o que é corroborado pela ausência de informações advindas da administração e desconhecimento por parte das presas. Embora, cada vez mais, haja a promoção de políticas públicas voltadas à saúde das pessoas em privação de liberdade, sua efetividade acaba esbarrando em problemas burocráticos, de infraestrutura e de falta de pessoal qualificado.

Com isso, entende-se a importância de se discutir e produzir acerca da saúde da população apenada, uma vez que são cidadãs e cidadãos, com todos os seus direitos garantidos pela Constituição Federal de 1988, como destacam Lima et al. (2013, p. 448):

Falar da saúde dos apenados enquanto direito não é uma face baseada meramente no arcabouço legal e normativo. A maioria das pessoas que se encontram nos presídios é culturalmente, socialmente e, por vezes, fisicamente mais frágil, estando assim mais vulneráveis e, por consequência, mais disponíveis para o adoecimento. $\mathrm{E}$ isso remete aos direitos humanos uma forma de buscar dignidade para essas pessoas.

Nesse contexto, considerando todas as perdas que uma pessoa em cumprimento de pena vivencia, o contato com familiares, amigos e companheiros é explicitado como fundamental para a manutenção da saúde mental das mulheres no contexto prisional. Isso se torna preocupante quando se discute o aprisionamento feminino, visto que frequentemente as mulheres são expostas ao abandono familiar e social, seja pelas dificuldades na visitação nos presídios, seja porque os familiares não mantêm o contato após a prisão (Oliveira, \& Santos, 2012).

Coelho (2010) aponta, em sua pesquisa, que as mulheres vivenciavam processos contraditórios ao expressar uma imagem de forte e inabalável, ao mesmo tempo que conviviam com sentimentos como mágoa e tristeza, sendo estes consequências diretas do abandono familiar. Dessa forma, para a autora, a mulher em privação de liberdade passa cada vez mais a se identificar somente com as características desenvolvidas enquanto presidiária, impossibilitando ou prejudicando uma reinserção social efetiva. Para Lima et al. (2013), as histórias de vida dessa população são marcadas por vínculos familiares precários, círculos pequenos de suporte social, baixos índices de sociabilidade e vivência de diversas formas de violência. Aliado a esses fatores, a prisão torna-se fonte de estigmatização, culminando no preconceito e impossibilidade de conseguir emprego após o desligamento da instituição.

Entende-se, portanto, que a investigação dos aspectos psicológicos envolvidos no processo de encarceramento, dentre outros fatores, aliado às questões de gênero demonstram ser um campo fundamental para a pesquisa e atuação dos profissionais da Psicologia, entendendo que estes perpassam por fatores sociais e históricos, que antecedem o aprisionamento. Para compreendermos melhor esse contexto, iremos utilizar os levantamentos nacionais produzidos pelo Estado, para, posteriormente, analisarmos as possibilidades em pesquisa nesse campo.

\section{Infopen Mulheres 2014 e 2018: questões para a Psicologia}

O Levantamento Nacional de Informações Penitenciárias constitui-se como um aparato importante ao Estado, que foi sendo aprimorado ao longo das últimas décadas para a promoção de mudanças assertivas na gestão prisional. Isso ocorreu principalmente após o fortalecimento e valorização da coleta e análise de dados nacionais, possibilitando que as políticas de segurança pública cada vez mais fossem 
voltadas à realidade prisional e às especificidades regionais (Brasil, 2018).

A evolução desse processo, concentrada principalmente após o levantamento de 2014, teve como consequência a elaboração, no mesmo ano, de um relatório específico sobre a população feminina que está nos presídios, demarcando a importância do olhar sobre as diferenças de gênero no processo de prisonização. Dessa forma, o Infopen Mulheres pode contribuir para a análise do contexto prisional feminino, suas lacunas e possibilidades de atuação, além de possibilitar uma visibilidade para um público-alvo historicamente esquecido (Brasil, 2014). Já em sua segunda edição lançada em 2018, com informações coletadas em Junho de 2016, o levantamento feminino propõe questionamentos mais amplos, levando em consideração diversos marcadores sociais como etnia, idade, gestação, entre outros temas relacionados às mulheres em situação de prisão (Brasil, 2018).

\section{Contexto do aprisionamento feminino: dados gerais e infraestrutura}

A partir de uma análise dos dados informados, em 2014 o Brasil possuía 37.380 mulheres cumprindo penas em privação de liberdade, constituindo a quinta maior população carcerária feminina do mundo, com números menores que os Estados Unidos, China, Rússia e Tailândia. Em paralelo, a taxa de aprisionamento entre os anos de 2000 e 2014 demonstrou números alarmantes, cerca de 567\%, sendo expressivamente maior que o crescimento da população de homens na prisão, que ficou por volta de $220 \%$ e que conta com um quantitativo total maior que as mulheres. Já no levantamento de 2018, o Brasil ultrapassa a Tailândia, tornando-se assim o quarto país com maior população prisional feminina, com um total de 42.355 mulheres em unidades carcerárias e um déficit de 15.326 vagas para mulheres nessas instituições, o que reproduz a concepção de um sistema penitenciário superlotado e insalubre, que desrespeita os direitos básicos dessa população (Brasil, 2014; 2018).

No que tange às unidades federativas, o estado de São Paulo, Minas Gerais e Rio de Janeiro figuram entre as maiores populações absolutas de mulheres presas no país, cerca de $58,2 \%$ em 2014 e $49 \%^{1}$ em 2018. A partir da comparação entre os levantamentos, destaca-se o caso do Paraná e do Mato Grosso que, no levantamento de 2014, eram os únicos estados que indicavam uma redução na população carcerária feminina de $-42 \%$ e $-29 \%$, entre os anos de 2007 e 2014, contando com uma população de 898 e 496 mulheres cumprindo penas, respectivamente. Entretanto, no relatório de 2018, o Paraná aparece com a terceira maior população carcerária entre os estados brasileiros, com um total de 3.251 mulheres, estando atrás somente de São Paulo e Minas Gerais, enquanto que o Mato Grosso há 727 mulheres, ocupando a 15a posição e demonstrando um crescimento populacional mais discreto (Depen, 2014, 2018). Ressalta-se que esses dados não são discutidos na versão mais atual do levantamento e podem indicar diversos questionamentos, dentre eles, a indisponibilidade de informações preenchidas por todas as instituições estaduais, levando a crer inicialmente na diminuição da população ou mesmo a confirmação dos dados apreciados que demonstram um aumento alarmante da população prisional feminina nos estados citados, mesmo com uma redução no ano de 2014.

Quanto à natureza da prisão e tipo de regime, os dados de junho de 2014 e de 2018 demonstram um aumento no número de mulheres encarceradas que não possuem condenação, passando de $30,1 \%$ para $45 \%$ da população feminina, sendo seguidos por sentenciadas em regime fechado, semiaberto e aberto. Isso se agrava quando se percebe que apenas $27 \%$ das unidades femininas são destinadas às presas provisórias. Vale destacar também que no estado do Amazonas, a porcentagem de mulheres sem decisão condenatória chega a $81 \%$. No entanto, o levantamento não oferece nenhuma hipótese que justifique um número tão alto de presas provisórias.

Algo que é discutido pelo Infopen Mulheres de 2018 refere-se ao fato de que essa porcentagem poderia ser ainda maior, visto que o levantamento não conseguiu abarcar informações sobre mulheres nas carceragens de delegacias. Isso significa que a ausência do recorte de gênero estaria muitas vezes mascarando a dificuldade expressiva que as mulheres enfrentam para ter acesso ao auxílio jurídico em seus processos. Além disso, essa alta demanda de presas provisórias também pode estar relacionada à entrada e à rotatividade crescente de mulheres no contexto criminal e, consequentemente, ao aprisionamento. Esse fator também sinaliza um problema

${ }^{1}$ Porcentagem calculada pelos autores, a partir do número populacional informado no Infopen Mulheres (Brasil, 2018). 
no cenário prisional feminino: a quantidade de estabelecimentos prisionais.

A superlotação e as condições precárias das instituições prisionais são destacadas por Amorim (2017) como as principais dificuldades vivenciadas nesse âmbito, influenciando diretamente na recorrência de episódios de fugas, rebeliões e sobrecarga do trabalho dos agentes penitenciários. A destinação de estabelecimentos de acordo com o gênero é um dever estatal, estando previsto na Lei de Execuções Penais - LEP (Lei 7.210, de 11 de julho de 1984) e afeta pontualmente as políticas públicas voltadas para esse público. Nesse sentido, pudemos perceber uma mudança comedida no destinamento das prisões para homens e mulheres trazidos nos levantamentos. Enquanto que em 2014, 1.070 unidades eram voltadas para o público masculino, 103 para o público feminino e 239 eram mistos, em 2018 há uma contida modificação, com 1.067 prisões masculinas, 107 femininas e 244 mistas, levando-nos a crer numa abertura, ainda que tímida, à oferta de vagas no encarceramento feminino. Outro ponto a se considerar refere-se ao número de instituições que não disponibilizaram essa informação, que passou de oito para 31 estabelecimentos (Brasil, 2014; 2018).

Cada vez mais as prisões mistas são tidas como uma opção para o aumento da população carcerária feminina, visto que estas se configuram com uma arquitetura prisional e serviços penais voltados incialmente para o público masculino e que, posteriormente, são adaptadas celas e alas para o aprisionamento de mulheres. Em sua maioria, por essas mudanças estruturais, esses estabelecimentos mistos não estão habilitados a oferecer espaços e serviços adequados a esse público-alvo, como profissionais voltados para a saúde da mulher, espaços específicos para as gestantes ou para o aleitamento, entre outros (Colares, \& Chies, 2010). Esses fatores contribuem de modo direto na invisibilidade das mulheres no ambiente penitenciário.

Em sua pesquisa realizada em estabelecimentos mistos do Rio Grande do Sul, Colares e Chies (2010) passam a utilizar a categoria nomeada por eles de "presídios masculinamente mistos", demarcando a organização ambígua nessas gestões prisionais, em que são aceitos tanto homens quanto mulheres, mas que é possível identificar um modelo androcêntrico, expresso na organização dos espaços, na divisão laboral, nas regras e punições disciplinares, representando assim a opressão que as mulheres sofrem em cárceres estruturalmente masculinos.
Outro fator preocupante quanto à estrutura dos estabelecimentos penais diz respeito ao fato de apenas $14 \%$ das unidades femininas ou mistas possuírem instalações de berçário e/ou centros de referência materno-infantil para que a mãe privada de liberdade tenha um lugar adequado para exercer a maternidade por determinado período, que geralmente se dá até os dois anos de idade da criança. Esse número é menor ainda quando se investiga o número de creches $(2 \%)$ voltadas a receber crianças acima de dois anos dentro das instituições femininas.

Diante desse contexto, a Lei $\mathrm{n}^{\circ} 13.257$ (2016), que dispõe sobre as políticas públicas para a primeira infância, trouxe algumas alterações nos artigos do Código de Processo Penal, entendendo que mulheres que ainda não foram condenadas, podem solicitar judicialmente a substituição da pena privativa por prisão domiciliar. Essa sentença se estende para gestantes, mulheres com filhos de até 12 anos de idade incompletos e homens que sejam comprovadamente os únicos responsáveis pelos cuidados de seus filhos de até 12 anos incompletos. Entretanto, essa decisão fica subjugada ao entendimento do juiz de que o interno em questão não oferece risco à ordem pública e podem cumprir a pena em regime domiciliar.

\section{Perfil das mulheres apenadas: uma questão interseccional}

Para a análise de quem são as pessoas que estão atualmente no sistema prisional feminino, os levantamentos nacionais apresentam categorias como faixa etária, etnia, escolaridade, estado civil, dentre outros, para compor o perfil sociodemográfico das mulheres que estão em cumprimento de pena em privação de liberdade. No que tange à idade, $50 \%$ da população feminina possui entre 18 e 29 anos, seguido por $18 \%$ com 30 a 34 anos, $21 \%$ com 35 a 45 anos, $9 \%$ com 46 a 60 anos, $1 \%$ com 61 anos a 69 e $1 \%$ com 70 anos ou mais. O Infopen Mulheres de 2018 ressalta ainda que a chance de mulheres na faixa de 18 a 29 anos serem presas é quase três vezes maior do que o aprisionamento de mulheres com idade acima de 30 anos, reforçando o ideário de que o sistema prisional é composto, em sua maioria, pelos jovens, tanto homens quanto mulheres. Destaca-se também que não houve mudanças na faixa etária dessa população entre os levantamentos realizados em 2014 e 2018 (Brasil, 2014; 2018). 
Sobre a raça/etnia, os relatórios pontuam a maioria da população negra dentro dos presídios, constituindo $68 \%$ da população carcerária feminina em 2014 e $62 \%$ em 2018, sendo seguido por brancas, com porcentagens entre 31\% em 2014 e 37\% em 2018, o 1\% restante refere-se a amarelas e indígenas e não houve variação ao longo dos levantamentos. Além disso, é pontuado que embora a coleta de dados sobre raça/etnia trabalhe com as categorias dispostas pelo Instituto Brasileiro de Geografia e Estatísticas - IBGE (branca, preta, parda, amarela ou indígena), que são autodeclarativos, as variáveis coletadas pelos Infopen são preenchidos por seus gestores prisionais e não há controle sobre a autodeclaração de tais características, podendo então haver interferências (Brasil, 2014; 2018).

Quanto ao grau de escolaridade, notou-se que em 2014, cerca de $72 \%$ das mulheres apenadas não possuía o nível médio de ensino, tendo concluído, no máximo, o ensino fundamental. Em 2018, houve uma leve variação, onde esse público diminui para $66 \%$ e destaca-se alguns estados como Alagoas e Rio Grande do Norte, onde os índices de mulheres analfabetas chega a $20 \%$. Embora esses dados estaduais sejam alarmantes, em geral, o número de pessoas com ensino médio completo aumentou de $10 \%$ para $15 \%$, podendo estar relacionado aos esforços das políticas públicas de administração penitenciária em promover o acesso à educação dentro do sistema (Brasil, 2014; 2018).

Em relação ao estado civil, mais da metade das mulheres encarceradas são solteiras $(57 \%$ em 2014 e $62 \%$ em 2018), o que pode ser favorecido também pela faixa etária ser predominantemente de jovens. Além disso, outro dado importante refere-se ao fato de $74 \%$ desse público possuir filhos, algo contrastante com a realidade masculina que chega a $46 \%$ (Brasil, 2018).

Ao avaliar o tipo de crime cometido, podemos perceber como o contexto prisional feminino está relacionado com padrões de criminalidade diferentes do encarceramento masculino, visto que, em 2014, enquanto apenas $25 \%$ dos crimes cometidos por homens referiam-se ao tráfico, para as mulheres essa proporção chegou a $68 \%$, sendo seguido por furto (9\%) e roubo (8\%). Já em 2018, $62 \%$ das incidências penais respondidas por mulheres em privação de liberdade referem-se a crimes ligados ao tráfico de drogas, além de roubo (11\%) e furto (9\%), o que demonstra uma seletividade tanto no encarceramento de determinados grupos sociais quanto na punição de crimes específicos, como é o caso dos crimes patrimoniais e crimes ligados ao tráfico.

Além disso, o tempo total de pena revela ainda o tratamento penal diferenciado ao qual as mulheres são submetidas, visto que:

[...] embora 29\% da população prisional feminina seja condenada a penas inferiores a 4 anos, apenas $7 \%$ das mulheres encarceradas no Brasil em Junho de 2016 cumpria pena em regime aberto. Da mesma forma, temos $41 \%$ da população condenada a penas entre 4 e 8 anos e o regime semiaberto contempla apenas $16 \%$ do total da população prisional feminina (Brasil, 2018, p. 56).

Percebe-se que, embora as mulheres cumpram penas de menor tempo aliado a crimes de menor potencial violento, ainda assim estas passam por processos morosos e são privadas de sua liberdade por tempo maior que o previsto em lei. Esses fatores reforçam nossa hipótese de um sistema penal androcêntrico, que pune as mulheres com base em um discurso moral e utiliza o encarceramento como repreensão (Vidal, \& Santos, 2016). Mais que isso, esses dados acerca do perfil das mulheres apenadas apontam para uma questão interseccional. Entendemos que este perfil é atravessado por questões históricas no Brasil, tais como a de classe, a étnico-racial e a de gênero, de maneira indissociável. Isso sem mencionar a importantíssima dimensão da diversidade sexual, que é invisibilizada nos Infopen.

Crenshaw (2002, p. 177) aponta que:

[...] interseccionalidade é uma conceituação do problema que busca capturar as consequências estruturais e dinâmicas da interação entre dois ou mais eixos da subordinação. Ela trata especificamente da forma pela qual o racismo, o patriarcalismo, a opressão de classe e outros sistemas discriminatórios criam desigualdades básicas que estruturam as posições relativas de mulheres, raças, etnias, classes e outras. Além disso, a interseccionalidade trata da forma como ações e políticas específicas geram opressões que fluem ao longo de tais eixos, constituindo aspectos dinâmicos ou ativos do desempoderamento.

Esta perspectiva interseccional nos ajuda a pensar a situação revelada pelos Levantamentos acerca 
das mulheres apenadas. Como os dados do Depen (Brasil, 2014; 2018) revelam, as mulheres que estão sendo presas no Brasil são jovens, com baixa instrução escolar, negras, vinculadas ao tráfico ou ao roubo / furto (pobres). Existe um perfil de aprisionamento estreitamente relacionado com nossa organização social fora dos muros das prisões. Mulheres negras, mães solteiras, pobres, expostas ao processo histórico e social de marginalização interseccional. O crime e o aprisionamento são consequências. Antes, há um processo de direcionamento específico deste "perfil" de mulher para marginalização social, determinado pela desigualdade social, pelo racismo e pelo patriarcalismo. A partir desta perspectiva, os Infopen apontam que um problema a ser discutido é esse processo demarcado historicamente que vem produzindo mulheres no contexto criminal. Antes de ser uma questão de polícia e jurídica, é uma questão de organização social, que através da análise interseccional, poderá ser problematizada. Assim, mais que pensar sobre o aumento da população carcerária feminina, faz-se necessário entender que mecanismos sociais direcionam mulheres negras e pobres ao sistema penitenciário, e intervir sobre estes.

\section{Educação e Trabalho: dimensões psicológicas}

A assistência ao preso é um direito assegurado na Lei de Execução Penal (Lei no ${ }^{\circ} .210$, de 11 julho de 1984), com o objetivo de prevenir a reincidência criminal e promover o retorno ao convívio social, estando direcionada às ações de assistência material, à saúde, jurídica, social, religiosa e educacional. A lei dispõe que a assistência educacional será voltada à instrução escolar e à formação profissional dos internos, sendo o ensino do primeiro grau de caráter obrigatório e integrado ao sistema escolar da Unidade Federativa.

Embora o acesso à educação seja um direito garantido em lei à pessoa privada de liberdade, o Infopen informou que apenas $25 \%$ da população carcerária feminina está participando de algum tipo de atividade educacional, seja no ensino escolar regular ou em atividades complementares, tais como os programas de remição de pena pela leitura ou participação em esportes. Esses dados se mantêm constantes nos levantamentos de 2014 e 2018, entretanto, o que nos chama atenção é que, assim como pontuamos o alto índice de analfabetas no estado do Rio Grande do Norte, em 2014 o estado apresentava um dos mais altos índices de alfabetização, chegando a $75 \%$ da população analfabeta, dado esse que aparece significativamente menor em 2018, onde apenas $1 \%$ de sua população carcerária feminina ingressou em algum nível de escolarização (Brasil, 2014; 2018).

Esses dados demonstram a precariedade da oferta educacional dentro das prisões, além da existência de poucos profissionais dispostos e preparados para trabalhar nessas instituições, tendo como consequência o baixo engajamento pelas internas, bem como a ineficiência dos programas propostos. Para Ireland e Lucena (2016), esses fatores dificultam a mudança nos projetos de vida e redirecionamento dessas mulheres. Os autores pontuam ainda que os projetos com potencial de aprendizagem muitas vezes são colocados como concorrentes, não havendo, portando, qualquer articulação entre eles. Além disso, esses projetos frequentemente são formulados de forma geral, ou seja, são pensados para o público masculino e executados nas instituições femininas, negando ou ignorando qualquer especificidade de gênero. Isso faz com que, na maioria das vezes, as detentas não vejam a educação como uma possibilidade de desenvolvimento e alternativa real de crescimento.

De acordo com Souza, Nonato e Bicalho (2017), a oferta educacional perpassa por uma lógica inclusão/ exclusão, visto que a população encarcerada possui uma vivência, em sua maioria, marcada pela desigualdade social e a educação seria um dos instrumentos responsáveis por promover o sentido de inclusão, bem como uma valorização pessoal, fortalecimento da autoconfiança e projeto de vida. Nesse sentido, as práticas educativas nos estabelecimentos prisionais permitiriam o acesso a serviços anteriormente negligenciados, tendo como consequência o sentimento de pertença social. Todavia, as autoras complementam que, ainda partindo da lógica exclusão/inclusão, pode-se compreender que no processo de encarceramento feminino, no qual o objetivo principal seria preparar os indivíduos ao retorno ao convívio social, a possibilidade de inclusão educacional não se efetiva, visto que não há vagas para todas e os projetos propostos não são voltados às necessidades dessas mulheres.

Em congruência com isso, Mayer (2013) pontua que a demanda por educação dentro das penitenciárias é decorrente da preocupação da gestão prisional em preencher o tempo livre dos internos. Além disso, o autor pondera sobre a constituição da prisão enquanto antieducativa, principalmente quando se 
volta a essa fixação de uma personalidade criminosa, e propõe, como alternativa, práticas que não buscam somente a escolarização, mas uma aprendizagem útil para a vida. Dessa forma, para favorecer o processo educacional, é necessário que se resgate a dignidade dos indivíduos. Mais do que apenas um detento, o sujeito apenado precisa legitimar-se enquanto educando e reconhecer a si e aos outros enquanto responsáveis por suas trajetórias.

Aliado à educação, as atividades laborais possuem um papel importante nas propostas de reinserção social, sendo um direito previsto em lei. Nesse sentido, o trabalho deverá assumir uma perspectiva tanto produtiva, quanto educativa, podendo se caracterizar como interno ou externo à instituição prisional (Lei ${ }^{\circ}$ 7.210, 1984). Em comparação com os levantamentos realizados em 2014 e 2018, houve uma diminuição da população carcerária feminina que está envolvida em atividades laborais, passando de $30 \%$ para $24 \%$. Além disso, o número de vagas demonstra ser predominantemente interno, passando de $75 \%$ para $87 \%$ em 2018, sendo composto tanto por atividades de apoio à administração da própria prisão, como é o caso dos serviços gerais, alimentação e jardinagem, quanto por atividades feitas em parcerias com outras instituições por meio de oficinas. A garantia de trabalho remunerado, que deveria ser ao menos $3 / 4$ do salário mínimo assegurado pela LEP, não é cumprido em pelo menos $63 \%$ dos trabalhos realizados por mulheres em privação de liberdade, que recebem menos que o estipulado ou não recebem nenhum tipo de remuneração.

Esse cenário é preocupante e corrobora com os achados de Mayer (2013) e Ireland e Lucena (2016) que retratam a atividade laboral como algo raro nas prisões, sejam elas femininas ou masculinas. Geralmente o trabalho ofertado não possui nenhuma perspectiva de crescimento profissional e não leva em consideração as experiências e habilidades desenvolvidas anteriormente ao cárcere. Para Mayer (2013), esse contexto contribui para a desvalorização do trabalho formal pelos apenados, vendo este como algo maçante, sem sentido e que perpetua as injustiças sociais.

Além disso, Ireland e Lucena (2016) pontuam a reprodução de diferenças de gênero a partir da divisão dos trabalhos entre as mulheres apenadas, em que a ocupação exercida se referia diretamente à identidade de gênero e orientação sexual dessa população. As mulheres categorizadas como heterossexuais desenvolviam atividades notadamente relacionadas a "carreiras femininas" como, por exemplo, cozinheiras, costureiras e artesãs. Já para as mulheres que se identificavam como lésbicas ou possuíam características físicas masculinizadas, as atividades diziam respeito a práticas como a de serviços gerais, jardinagem, entre outros.

Entendemos todas essas questões como inerentes às preocupações da Psicologia. A despeito de uma intervenção na organização social para evitar o aprisionamento interseccional de algumas mulheres, a Psicologia pode atuar dentro e para o sistema penitenciário com a finalidade de garantir a constituição de posicionamentos subjetivos diante do processo criminal e prisional. Nesse sentindo, a abertura que as atividades educacionais e laborais dão para isso deve ser valorizada pelos profissionais de Psicologia; bem como as possibilidades de pensar e prospectar esses campos como espaço de promoção de saúde, podem se constituir como desafios para a pesquisa psicológica.

\section{Desafios para a pesquisa em Psicologia no sistema penitenciário feminino}

Conclusões acerca da situação do aprisionamento feminino podem ser tiradas a partir dos dados apontados na comparação do Infopen Mulheres 2014 com o de 2018. Essas conclusões nos conduzem para pensar como tais situações dizem respeito à profissão Psicologia e também como apontam caminhos e desafios para a pesquisa psicológica nesse contexto. Essa preocupação também é percebida pelo Conselho Federal de Psicologia que vem lançando diversos regulamentos buscando compreender a atuação de psicólogos nesse contexto, bem como regulamentar os fazeres da ciência psicológica e o que não se constitui como demanda desta.

O Infopen Mulheres de 2018 revelou que o Brasil atualmente possui a quarta maior população carcerária do mundo, sendo que desta mais de 42 mil pessoas são mulheres. Um agravante deste cenário é que o sistema penitenciário possui uma defasagem de mais de 15 mil vagas, ou seja, em um espaço que cabem três mulheres, têm-se quase cinco pessoas presas. Os impactos dessa realidade atuam diretamente no atendimento dos direitos básicos dessas mulheres. Pensar soluções para esse fato passa necessariamente por pesquisas que apontem o processo social, histórico, cultural e psicológico que intervêm na inserção de mulheres na criminalidade, mas também na lógica do aprisionamento, bem como das condições psíquicas que são produzidas no encarceramento feminino. 
Tal cenário pode ser ainda mais problematizado quando percebemos que o maior crescimento no que tange tipo de pena se deu entre as mulheres ainda sem condenação, atualmente $45 \%$ da população feminina, isto é, estima-se que quase 19 mil mulheres estão sob condições insalubres que afetam sua dignidade e seu processo de subjetivação mesmo ainda não tendo o seu processo julgado. Este número de $19 \mathrm{mil}$, inclusive, supera a defasagem de 15 mil vagas no sistema penitenciário feminino. Mais uma vez, destacamos que há um problema social a ser investigado e problematizado. Por que prendemos tanto e criamos as condições desfavoráveis para esse aprisionamento, seja de ordem jurídica e burocrática ou de investimento e preocupação governamental? E quais repercussões de tal problema atingem essas mulheres? O que a Psicologia pode promover como conhecimento para a resolução desse problema?

A solução dada pelo Estado para o aumento da população carcerária feminina e a falta de infraestrutura vem se direcionando para um maior investimento nas penitenciárias mistas, visando um menor gasto financeiro e aproveitando os espaços já destinados às penitenciárias masculinas. Essa solução se desdobra em outros problemas e desafios, no que se refere à questão das relações de gênero. Pois nestes espaços, a lógica de funcionamento é pensada para os homens, não há estrutura básica, como espaço para amamentação, berçário e creches, e ocorre o processo de anulação das especificidades das mulheres presas, na rotina e nas atividades. As relações sociais patriarcais, a invisibilidade feminina, a falta de condições essenciais para a afirmação da identidade de gênero faz com que o sistema penitenciário se transforme em um refinamento cruel das relações de gênero desiguais que pautam a história da sociedade brasileira. Subjetividade, identidade, relações interpessoais, saúde são objetos históricos da Psicologia. Esse cenário, por si, aponta inúmeras possibilidades de investigações na área, tal como se dão as relações entre as internas, com o corpo técnico, com a família, no que se refere a sua construção subjetiva como mulher. Também se faz necessário investigar a questão da maternidade, diante de tantas mães solteiras aprisionadas.

Quando os Infopen apontam o perfil de quem são essas mulheres, o campo de estudo e de necessidade de intervenção se torna ainda mais complexo e aumenta as demandas por pesquisas. Como apontamos acima, as prisões brasileiras foram construídas para um público específico, no caso das mulheres, esse público fica evidenciado nos dados de 2018. A mulher apenada brasileira é jovem, pobre, negra, constituída socialmente pelo abandono dos pais de seus filhos, pela falta de estudos escolares, de acesso ao mundo do trabalho e tomada pela criminalidade, principalmente para práticas mais susceptíveis de aprisionamento no tráfico de drogas. Relações de gênero, classe social, relações étnico-raciais se entrelaçam na análise interseccional para compreender tal fenômeno histórico, cultural e social (Crenshaw, 2002). Uma Psicologia construída com compromisso social deveria urgentemente se implicar nesse quadro. Desde a formação de novos profissionais, mas especialmente na produção de conhecimento que desvele e intervenha nesse processo. Psicologia Social, Jurídica, Escolar e Educacional, do Trabalho, da Saúde, Avaliação Psicológica, entre outras, historicamente consolidaram conhecimentos acercas das relações apontadas na constituição do perfil das mulheres presas. A combinação entre esses fatores que a noção de interseccionalidade aponta é um mecanismo perverso de condução de corpos e anulação de perspectivas para essas mulheres.

Assim como também faz necessário investigar e avaliar os mecanismos estatais de "ressocialização" engendrado, em destaque, pela assistência a educação e ao trabalho. Os dados dos Infopen Mulheres apontam para um entendimento que esses mecanismos estão falhando na sua execução. Apenas $25 \%$ da população feminina carcerária está envolvida com atividades educacionais, esse número se repete também em relação as atividades laborais. Considerando esses dois fatores como essenciais para um trabalho de dimensão psicológica no fortalecimento dos processos de construção de si das mulheres presas, diante do cenário externo opressor e das opressões dos processos burocráticos e jurídicos, esse baixo índice é preocupante. Consideramos que notadamente a atuação em Psicologia nessas atividades pode fomentar novas perspectivas sociais de resistências dessas mulheres. Pesquisas que produzam conhecimentos específicos sobre os processos educacionais e laborais para mulheres apenadas são caminhos viáveis para um maior fortalecimento dessa assistência, principalmente diante dos dados sociais do perfil dessas mulheres e de suas vivências durante o aprisionamento.

Para Mello, Silva, Rudnicki e Costa (2017), a riqueza no campo empírico da prisão reflete também as dificuldades enfrentadas pelos pesquisadores. Os 
estudos realizados na área prisional perpassam não só por fatores como a rotina e o processo de institucionalização, mas por relatos de violência, insegurança, condições precárias, que aparecem nas falas das internas e de funcionários e que retratam uma realidade social difícil. Nesse sentido, alguns fatores são citados enquanto desafios empíricos, sendo os Comitês de Ética e Pesquisa com Seres Humanos o primeiro a confrontar os pesquisadores. Os autores ressaltam que frequentemente os avaliadores não possuem o conhecimento do campo e suas peculiaridades, propondo modificações que inviabilizam alguns aspectos dos estudos de cunho qualitativo no sistema penal. O tempo também é apontado como imprevisível, visto que o desenvolvimento desses estudos nunca é linear e dependem de diversos elementos para sua efetivação. Além disso, encontra-se resistência por parte dos agentes penitenciários e direção que, de certa forma, buscam ter um controle sobre as informações veiculadas à instituição.

Em suma, os desafios não são poucos para que a Psicologia se engaje na mudança desse quadro que os Infopen Mulheres apontam acerca do sistema penitenciário feminino. Questões sociais complexas com repercussões sobre a subjetividade e identidade dessas mulheres se destacam nos Levantamentos. Sistema prisional e segurança pública não devem ser temas de discussão de apenas uma área específica, mas devem ser entendidos com cenários sociais que revelam questões sociais, e a Psicologia, enquanto ciência e profissão, essencialmente social, deve atuar sobre estas questões.

\section{Considerações finais}

A realização deste estudo permitiu que fosse possível compreender o contexto prisional feminino através dos Infopen Mulheres publicados em 2014 e 2018, possibilitando a análise da evolução do encarceramento feminino ao longo dos anos, a infraestrutura disponível, o perfil de mulheres em conflito com a lei, bem como algumas dimensões psicológicas produzidas no processo assistencial, levando em consideração os serviços laborais e educacionais ofertados a esse público.

Nesse sentido, percebe-se que o sistema prisional enquanto campo de atuação e pesquisa revela-se perpassado por relações de poder, saberes e práticas normativas que visam produzir determinados tipos de subjetividade. A interseccionalidade torna-se uma ferramenta extremamente útil para os pesquisadores, diante de um cenário que envolve marcadores de gênero, relações étnico-raciais e econômicas.

Nessa direção, a realidade é vivenciada pela mulher apenada de forma mais severa, visto que além da precariedade das instituições carcerárias, há uma negação das especificidades de gênero, sendo reproduzidos serviços penais direcionados aos homens. Além disso, as internas passam por uma dupla culpabilização - a da justiça e da sociedade. Ao serem condenadas, as mulheres são abandonadas e passam a vivenciar o sentimento de solidão, que ocorre pelo afastamento de amigos e parentes e pela escassez de visitas.

Para Braga (2015), o reconhecimento dos direitos das mulheres configura-se de maneira seletiva e perversa, proporcionando um acesso à justiça limitado e perpassado por estigmas que busca repreender qualquer comportamento que desvirtue do lugar simbólico atribuído à mulher na sociedade. Consequentemente, o sistema penitenciário reflete essas práticas normativas, constituindo-se como um sistema sexista, que demarca hierarquias de gênero e privilegia ações voltadas aos homens em privação de liberdade.

Percebe-se, portanto, a necessidade da Psicologia, enquanto ciência implicada com mudanças sociais e garantia de direitos, se apropriar cada vez mais do contexto prisional enquanto campo de pesquisa, levando a sociedade, seja ela acadêmica ou não, a refletir sobre a proposição da instituição prisional enquanto projeto de ressocialização e auxiliar na formulação de políticas públicas e ações voltadas para um público historicamente socialmente esquecido.

\section{Referências}

Amorim, M. S. (2017). A privação de liberdade e o método APAC: Uma forma de ressocialização voluntária na execução da pena (trabalho de conclusão de curso). Departamento de Ciências Jurídicas e Sociais, Universidade Regional do Noroeste do Estado do Rio Grande do Sul, Porto Alegre, RS, Brasil.

Braga, A. G. M. (2015). Entre a soberania da lei e o chão da prisão: A maternidade encarcerada. Revista Direito GV, 11(2), 523-546. https://doi.org/10.1590/1808-2432201523 
Brasil. Ministério da Justiça. (2014). Levantamento Nacional de Informações Penitenciárias - INFOPEN Mulheres. Brasília, DF: o autor.

Brasil. Ministério da Justiça e Segurança Pública (2018). Levantamento Nacional de Informações Penitenciárias INFOPEN Mulheres (2a ed.). Brasília, DF: o autor.

Brasil. Ministério da Saúde. (2004). Plano nacional de saúde no sistema penitenciário. Brasília, DF: Ministério da Saúde. Recuperado de http://bvsms.saude.gov.br/bvs/publicacoes/cartilha_pnssp.pdf

Brasil. Ministério da Saúde. Secretaria de Atenção à Saúde. (2011). Política nacional de atenção integral à saúde da mulher: Princípios e diretrizes. Brasília, DF: o autor. Recuperado de http://bvsms.saude.gov.br/bvs/publicacoes/ politica_nacional_mulher_principios_diretrizes.pdf

Carvalho, D. T. P., \& Mayorga, C. (2017). Contribuições feministas para os estudos acerca do aprisionamento de mulheres. Estudos Feministas, 25(1), 95-112.

Coelho, S. C. R. (2010). Para além do cárcere: O significado reeducativo da pena privativa de liberdade em uma instituição penal para mulheres em São Luís (dissertação de mestrado). Universidade Federal do Maranhão, São Luís, MA, Brasil.

Colares, L., \& Chies, L. (2010). Mulheres nas so(m)bras: Invisibilidade, reciclagem e dominação viril em presídios masculinamente mistos. Estudos Feministas, 18(2), 407.

Crenshaw, K. (2002). Documento para o encontro de especialistas em aspectos da discriminação racial relativos ao gênero. Estudos Feministas, 10(1), 171.

Ireland, T. D., \& Lucena, H. H. R. (2016). Educação e trabalho em um centro de reeducação feminina: Um estudo de caso. Cadernos CEDES, 36(98), 61-78. https:// doi.org/10.1590/CC0101-32622016162651

Lei No 7.210, de 11 de julho de 1984. Institui a Lei de Execução Penal. Diário Oficial da União, 13 jul. 1984

Lei No 13.257, de 8 de março de 2016. Dispõe sobre as políticas públicas para a primeira infância e altera a Lei no 8.069, de 13 de julho de 1990 (Estatuto da Criança e do Adolescente), o Decreto-Lei no 3.689, de 3 de outubro de 1941 (Código de Processo Penal), a Consolidação das Leis do Trabalho (CLT), aprovada pelo Decreto-Lei no 5.452, de 1 o de maio de 1943, a Lei no 11.770, de 9 de setembro de 2008, e a Lei no 12.662, de 5 de junho de 2012. Diário Oficial da União, 9 mar. 2016.

Lima, G. M. B., Pereira Neto, A. F., Amarante, P. D. C., Dias, M. D., \& Ferreira Filha, M. O. (2013). Mulheres no cárcere: Significados e práticas cotidianas de enfrentamento com ênfase na resiliência. Saúde em Debate, 37(98), 446456. https://doi.org/10.1590/S0103-11042013000300008

Mayer, M. (2013). A educação na prisão não é uma mera atividade. Educação \& Realidade, 38(1), 33-49. https://doi. org/10.1590/S2175-62362013000100004

Mello, P. V., Silva, J. C., Rudnicki, D., \& Costa, A. P. M. (2017). Pesquisa empírica no sistema prisional: construindo experiências. Revista de Estudos Empíricos em Direito, 4(3). https://doi.org/10.19092/reed.v4i3.273

Meneghetti, F. K. (2011). O que é um ensaio-teórico?. Revista de Administração Contemporânea, 15(2), 320-332. https://doi.org/10.1590/S1415-65552011000200010

Oliveira, M. G. F., \& Santos, A. F. P. R. (2012). Desigualdade de gênero no sistema prisional: considerações acerca das barreiras à realização de visitas íntimas às mulheres encarceradas. Caderno Espaço Feminino, 25(1), 236-246.

Rolim, M. (2004). Prisão e ideologia: Limites e possibilidades para a reforma prisional no Brasil. Center for Brazilian Studies, 48, 38-85.

Silva, E. F., \& Ribeiro, E. R. (2013). Atenção à saúde da mulher em situação prisional. Saúde e Desenvolvimento, 4(2), $160-172$.

Souza, M. C. F., Nonato, E. M. N., \& Bicalho, M. G. P. (2017). Lógicas de exclusão/inclusão dos processos educativos no contexto prisional feminino. Educação \& Sociedade, 38(138), 45-61. https://doi.org/10.1590/es010173302016158634

Spink, P. (2013). Análise de documentos de domínio público. In: M. J. P. Spink (Org.), Práticas discursivas e produção de sentidos no cotidiano (pp. 79-105). São Paulo, SP: Cortez.

Vidal, J. P., \& Santos, D. L. (2016). Mulher e execução da pena: Instrumento de exclusão social e construção de uma cidadania de segunda classe. Conpedi Law Review, 1(10), 193-219. https://doi.org/10.26668/2448-3931_conpedilawreview/2015.v1i10.3407 


\section{Ramon Luis de Santana Alcântara}

Professor Adjunto na Universidade Federal do Maranhão (UFMA), São Luís - MA. Brasil. Professor Permanente no Programa de Pós-Graduação em Psicologia (PPGPSI) da UFMA.

E-mail: ramon.lsa@ufma.br

(iD) https:// orcid.org/0000-0001-6759-7399

\section{Carla Priscilla Castro Sousa}

Mestranda pelo Programa de Pós-Graduação em Psicologia da Universidade Federal do Maranhão (UFMA), São Luís - MA. Brasil.

E-mail: carlinha-pcs@hotmail.com

(iD https:// orcid.org/0000-0003-4711-5035

Thaís Stephanie Matos Silva

Graduanda em Psicologia pela Universidade Federal do Maranhão (UFMA), São Luís - MA. Brasil.

E-mail: thaisstephaniems@hotmail.com

(iD) https:// orcid.org/0000-0002-0068-4735

Endereço para envio de correspondência:

Av. dos Portugueses, 1966

Bacanga - CEP 65080-805

São Luís - MA

Recebido 17/08/2018

Aprovado 23/08/2018

Received 08/17/2018

Approved 08/23/2018

Recibido 17/08/2018

Aceptado 23/08/2018

Como citar: Alcântara, R. L. S., Sousa, C. P. C., \& Silva, T. S. M. (2018). Infopen Mulheres de 2014 e 2018: Desafios para a pesquisa em Psicologia. Psicologia: Ciência e Profissão, 38(n.spe.2), 88-101. https://doi.org/10.1590/1982-3703000212154

How to cite: Alcântara, R. L. S., Sousa, C. P. C., \& Silva, T. S. M. (2018). Infopen Women of 2014 and 2018: Challenges for research in Psychology. Psicologia: Ciência e Profissão, 38(n.spe.2), 88-101. https://doi.org/10.1590/1982-3703000212154

Cómo citar: Alcântara, R. L. S., Sousa, C. P. C., \& Silva, T. S. M. (2018). Infopen Mujeres de 2014 y 2018: Desafíos para la investigación en Psicología. Psicologia: Ciência e Profissão, 38(n.spe.2), 88-101. https://doi.org/10.1590/1982-3703000212154 